\title{
Proceeding
}

Supplementary Issue: Summer Conferences of Sports Science. Costa Blanca Sports Science Events, 20-21 September 2019. Alicante, Spain.

\section{Prediction of some types of handball throws according to the attention expressions of physical Education and sports Sciences female students}

\author{
HIND M. AMIN 14 , NOMAN A. KARIM², RANA A.W. JASSIM ${ }^{3}$ \\ ${ }^{1}$ College of Physical Education and Sports Sciences, Kufa University, Iraq \\ ${ }^{2}$ College of Physical Education, Qadisiyah University, Iraq \\ ${ }^{3}$ Department of Physical Education, College of Education for Girls, Qadisiyah University, Iraq
}

\begin{abstract}
The study aimed at the for certain types of throws, the attention aspects, the relationship between the throwing accuracy in handball and the attention expressions in handball for the second stage female students in the College of Physical Education Qadisiyah University. The hypothesis of the research included a statistically significant correlation between attention expressions and throwing accuracy in handball and making a prediction equation for throwing accuracy for certain types of throws using attention expressions for the second stage female students in the College of Physical Education Qadisiyah University. The researchers used the descriptive approach by the survey method. The sample was chosen in an intentional way, the search sample was deliberately chosen, and they are second stage female students in the College of Physical Education Qadisiyah University. 44 female students, (20) female students were chosen using the Simple Lottery method where the sample rate is $45,45 \%$ of the members are native community members. The exploratory experiment was conducted to ascertain used devices and tools, and this was accomplished and then the main experiment was performed in the final form and then the data was processed through the statistical bag SPSS and the time period of search was 18/3/2019-3/4/2019. The researcher extracted the prediction equations using the SPSS statistical program. The researchers concluded that the existence of a moral correlation between certain types of throws in handball and attention expressions for the second stage students in the College of Physical Education Qadisiyah University. Keywords: Handball; Attention expressions; Throwing accuracy.
\end{abstract}

\section{Cite this article as:}

Amin, H.M., Karim, N.A., \& Jassim, R.A.W. (2019). Prediction of some types of handball throws according to the attention expressions of physical Education and sports Sciences female students. Journal of Human Sport and Exercise, 14(5proc), S1842-S1852. doi:https://doi.org/10.14198/ihse.2019.14.Proc5.03

Corresponding author. College of Physical Education and Sports Sciences, Kufa University, Iraq.

E-mail: dr.ghafarsaeedissa@gmail.com

Supplementary Issue: Summer Conferences of Sports Science. Costa Blanca Sports Science Events, 20-21 September 2019. Alicante, Spain.

JOURNAL OF HUMAN SPORT \& EXERCISE ISSN 1988-5202

(c) Faculty of Education. University of Alicante

doi:10.14198/jhse.2019.14.Proc5.03 


\section{INTRODUCTION}

Prediction is a scientifically proven method based on metrics subjected to analysis and specific assessments which is one of the essential means for testing where a future prediction can speak of a phenomenon or behaviour so it is a science of probability supported by scientific observation of the future prediction of the situation. Forecasting is used in various fields to detect the attention expressions for athlete's performance and their impulses to exercise and maintain their abilities and capabilities, which is to conceptualize the results of using the information we have reached in new situations. the handball is one of team based games which is widely spread in many parts of the world, characterized by the beauty of individual and collective artistic performance also characterized by the performance speed at the level of individuals and teams and on the defensive and offensive side, which requires the physical care, technical, tactical requirements, modern science and modern psychological. in which the athlete tries to develop his focus and his attention as required by the skill performance and control the requirements of training and competition. Perhaps the most important characteristic of the handball game is its interaction with a lot of theoretical and applied sciences, including the cognitive aspect and it is closely linked to the aspect of intellectual equilibrium, because the students are in the skill acquisition stage, so it takes a great time to perform and that is what makes them require a lot of movements, Proper behaviour and need attention. The purpose of the research is to predict to which extent can attention expressions effects some types of throws in handball for female Physical Education students.

\section{Research problem}

It was noted that most female students acquire skill properly in terms of technique offensive and defensive performance in general, but when they perform the correction there is a high failure percentage and this requires the focus of attention to this, thus in order engage into this way the research problem lies with the following question:

About what is the relationship between the accuracy of the correction and the manifestations of attention that we can predict in the future?

\section{Research goals}

1. Identify the accuracy of the correction of some types of correction in handball and on the manifestations of attention among students of the second stage in the Faculty of Physical Education - University of Qadisiyah

2. Identify the relationship between the accuracy of correction in handball and manifestations of attention among students of physical education and sports science - University of Qadisiyah

\section{Research imposes}

1. There is a statistically significant correlation between the manifestations of attention and the accuracy of the correction of the hand wheel among students of physical education and sports sciences - Al-Qadisiya University

2. Finding an equation to accurately predict the correction of some types of correction manifestations of attention among students of physical education and sports sciences - University of Qadisiyah. 


\section{METHODS}

The researcher used a descriptive approach in the interconnectivity style for its suitability to solve the problem.

\section{Participants}

The search sample was deliberately chosen, and they are second stage female students in the College of Physical Education Qadisiyah University. 44 female students, (20) female students were chosen using the Simple Lottery method where the sample rate is $45,45 \%$ of the members are native community members.

\section{Measures}

Tools used in research:

1. Handball legal stadium, with 10 legal balls.

2. A tape with a width of $5 \mathrm{~cm}$

3. 7 plastic cones

4. 4 Iron Goal post size $40 \times 40 \mathrm{~cm}$ and 4 Iron Goal post size $50 \times 50 \mathrm{~cm}$ and 4 Iron Goal post size $60 \times 60 \mathrm{~cm}$.

Arabic and foreign sources.

\section{Tests used in research}

\section{Prdon-Invimov test}

The researcher used the Prdon Invimov test prepared by Abdeljawad Taha 1971 and is considered one of the tests for athletes which is used to measure five aspects of attention excretions (attention sharpness, attention focus, attention stability, attention distribution, attention shifting) as described in the form.

\section{Attention sharpness}

From the word start the player will flip the test model at the moment of clock operation and start to write off the number 47 in the last of each group.

The test time is only one minute.

\section{Correction method}

1. Count the total number of digits reached by the tested subject within one minute of the test until the stop directive. (l.e. the total size of the foreseeable symbolized by the symbol ' $A$ ').

2. Counting the number (47) that the tested subject has written off in the visible part, symbolized by the symbol $\mathrm{C}$ and extracted by a key which is a transparent sheet containing holes with the number of digits in the scale form. A key that specializes in one number differs from the other number which helps the researcher to extract the results quickly and accurately.

3. Count the number of digits that have been accidentally written off by the tested subject in the foreseeable part, symbolized by the symbol (W).

4. Count the numbers that the laboratory has not written off, i.e. forgotten in the visible part and it's symbolized by $(0)$

Attention acuity is extracted through the following equation: 


\section{Attention sharpness $=$ The numbers that has been correctly written-off numbers - The numbers that has been by mistake $=$ foreseeable numbers \\ The numbers that has been correctly written off numbers + The numbers that has been forgotten}

Note: The higher the sharpness output, the higher the sharpness level ${ }^{1}$

2. Attention concentration test

Instructions and tools

The performance system is the method used to measure attention sharpness but with a device (MetronumFlash) which gives (60) beep sound per minute with a flashlight every (5) seconds.

Which means (12) flashlight per minute as shown in figure (1) if the number (96) is written off and the test time takes only one minute.

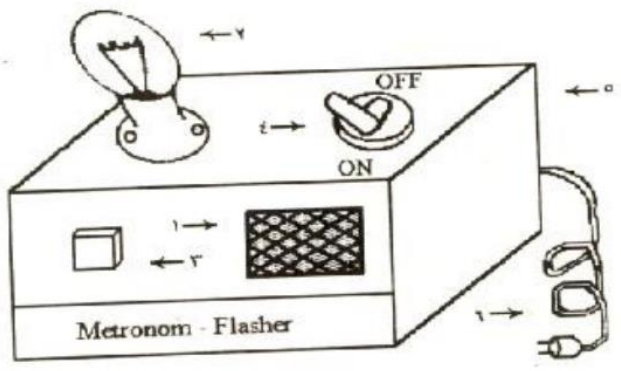

Figure 1. Explains metronom-flash.

The focus of attention is extracted from the following equation:

Focus attention = output of the sharpness test without effect (U1)- sharpness test with the presence of the light and acoustic effect (U2).

Note: The lower the indication (output) the higher the attention focuses level.

3. Attention Stability Test

Instructions:

The performance system is the same approach to measuring attention sharpness. The number (47) is selected for this test. The test time is two minutes. The net productivity of constant attention is extracted from the following equation:

1 Mustafa,.H. \& Mohammed, M. (1989). Attitudes of Athletes in Sports Activities (Comparative Study). Cairo, Egypt: Scientific Journal of Physical Education and Sports, Faculty of Physical Education for Boys 
The numbers that has been correctly written-off numbers - The numbers that has been by mistake

The numbers that has been correctly written off numbers + The numbers that has been forgotten $=100$

Note: The higher the stability level, the higher the stability level of the player.

4. Attention Distribution test Instructions:

Following the performance method in the same sharpness test in which some variables:

- When you give the word start with the clock running the player starts to search for two numbers at once these two numbers are $(69,92)$ which means he is looking for the two numbers at the same time, and when he notices either of them he starts writing it off until the signal (stop) is given.

- $\quad$ Test time 2 minutes.

- The attention sharpness of the number (96) (U3) is extracted as described in the sharpness test.

- $\quad$ Attention is drawn to the number (92) (U4) as described in the sharpness test.

- After extracting the result for the two digits $(96,92)$ the following equation is used to extract the result of the attention distribution:

Net sharpness result (u3) - Net sharpness result (u4)

Net sharpness result (u3) + Net sharpness result (u4)

Note: The lower the output of the attention distribution, the higher the appearance level of the player's attention distribution.

5. Attention shifting Test Instructions:

Variables are added to this test compared to previous tests. The player writes off the numbers $(49,96)$ but each number is separate from the other for (30) seconds and each number has two rounds and as shown below:

When the player hears the word (start) he writes off the number (49) only and for (30) seconds when the (30) seconds ends and he hears a word about the number (96) he puts the sign $(X)$ at the end and continue writing off the number (96).

When the player hears the word (start) he writes off the number (49) only and for (30) seconds when the (30) seconds ends and he hears a word about the number (96) he puts the sign $(X)$ at the end and continue writing off the number (96).

1. When he hears a word about the number (96) he writes off the number for (30) seconds more, when the time ends he hears the number (49) and puts the sign $(X)$ at the end and continue writing off the number (49). 
2. When he hears the word (complete) for the number (49) he continue putting the first $(X)$ sign and for another (30) seconds, when the time ends he hears the number (49) and puts the sign $(X)$ at the end and continue writing off the number (49).

3. When he hears the word (complete) for the number (96) he continues putting the second $(X)$ sign and for another $(30)$ seconds, when he finishes putting the $(X)$ sign the test ends.

4. Test time 2 minutes (one minute for each number).

Correction method is as following:

1. Intensity calculation is for (4) times (30) seconds same as the intensity calculation in the first test.

2. After that the difference between the first, second, third and fourth (30) seconds is calculated by subtracting one from the other to extract the net productivity as follows:

- $\quad(m)$ denotes the difference between labour productivity between the first- and second-time fractions $(m=u 1-u 2)$.

- $\quad(\mathrm{H})$ stands for the difference between work productivity between the second- and third-time fractions $(\mathrm{H}=\mathrm{U} 2-\mathrm{U} 3)$.

- $\quad(0)$ denotes the difference between work productivity between the third- and fourth-time fractions (o = u3-u4)

- $\quad$ The conversion of attention in the final equation is equal to $n=(m+h+0) \backslash 3$

Table 1. Handball throwing accuracy tests.

\section{Test Name}

Shoulder-level pivoting correction test

Aiming test from jumping high

Aiming accuracy test from jumping forward
Test goal

The accuracy of the correction from the fulcrum

Precision aiming of jumping high

Accuracy aiming of jumping forward

\section{Procedures}

The exploratory experiment was conducted on Monday, 18/3/2019, on a sample of 45 female students in the second stage, in order to determine the appropriate time for testing and the tests validity and the equipment availability that must be available for testing and the possibility of the auxiliary staff. The results obtained indicated that the tools required for testing are suited and availability, as well as getting rid of the difficulties that the researcher may encounter during the main experiment.

\section{Analysis}

Table 2. Shows the scientific basis of stability and objectivity of the tests under study

\begin{tabular}{lccc}
\hline T & Test & stability & objectivity \\
\hline 1 & Attention sharpness & 0.957 & 0.86 \\
2 & Focus attention & 0.999 & 0.85 \\
3 & Attention distribution & 0.787 & 0.76 \\
4 & Divert attention & 0.999 & 0.85 \\
5 & The throwing accuracy from over the & 0.945 & 0.94 \\
6 & head. & 0.756 & 0.89 \\
7 & Accuracy of aiming from jumping forward & 0.982 & 0.79 \\
8 & Aiming accuracy from the front fall & 0.999 & 0.85 \\
\hline
\end{tabular}


The researcher used honesty and after the tests presented the results to experts and specialists, the agreement percentage reached $100 \%$ on the test applicability and suitability. The test and re-test method have been used to find a stability coefficient. The test was evaluated by two judges to extract the test objectivity using the Pearson's simple correlation coefficient between the results obtained from the judges and the correlation values were high. As showing in Table 2.

\section{Main experiment}

The researchers conducted the main experiment on (Tuesday) corresponding to 2/4/2019 at ten am on the research sample and they are second grade students in the College of Physical Education and Sports Science - University of Qadisiyah. 3/4/2019 Attention tests were performed and after all tests the raw scores were recorded to be statistically processed.

\section{Statistical means}

The researcher used SPSS.

\section{RESULTS}

1. There is a correlation of moral correlation between some types of correction handball and manifestations of attention among students of physical education and sports sciences second stage University of Qadisiyah.

2. Prediction equations have been developed for some types of handball aiming according to the variables studied (sharpness of attention, attention concentration, attention stability, attention conversion.

3. For the predictability of the types of correction and according (shooting at the level of the shoulder according to the intensity of attention and correction of jumping high according to the concentration of attention and correction of jumping in front of the stability of attention and correction of the fall according to the attention shift.

First: To identify the relationship between some types of handball throwing accuracy and attention to students of the Faculty of Physical Education and Sports Sciences - Al-Qadisiyah University.

Table 3. Shows the correlation between some types of throwing accuracy and attention attributes.

\begin{tabular}{|c|c|c|c|c|c|c|}
\hline Aiming precision test & $\begin{array}{l}\text { Correlation } \\
\text { coefficient }\end{array}$ & $\begin{array}{l}\text { Attention } \\
\text { sharpness }\end{array}$ & $\begin{array}{l}\text { Focusing } \\
\text { attention }\end{array}$ & $\begin{array}{c}\text { Stability } \\
\text { of } \\
\text { attention }\end{array}$ & $\begin{array}{l}\text { Attention } \\
\text { distribution }\end{array}$ & $\begin{array}{l}\text { Divert } \\
\text { attention }\end{array}$ \\
\hline \multirow{2}{*}{$\begin{array}{c}\text { The aiming precision from } \\
\text { shoulder level }\end{array}$} & $\begin{array}{c}\text { Correlation } \\
\text { coefficient }\end{array}$ & 0.582 ** & 44.0 & ${ }^{*} 0.479$ & ${ }^{*} 0.506$ & ${ }^{* *} 0.563$ \\
\hline & $\begin{array}{c}\text { Significance } \\
\text { level }\end{array}$ & 007.0 & 0.051 & 0.032 & 0.022 & 0.009 \\
\hline \multirow{2}{*}{$\begin{array}{l}\text { Aiming precision of } \\
\text { jumping high }\end{array}$} & $\begin{array}{l}\text { Correlation } \\
\text { coefficient }\end{array}$ & ${ }^{*} 0.480$ & ${ }^{* *} 0.621$ & 0.434 & ${ }^{*} 0.487$ & *0.491 \\
\hline & $\begin{array}{c}\text { Significance } \\
\text { level }\end{array}$ & 0.032 & 0.003 & 0.055 & 0.029 & 0.027 \\
\hline \multirow{2}{*}{$\begin{array}{l}\text { Aiming precision from } \\
\text { jumping forward }\end{array}$} & $\begin{array}{l}\text { Correlation } \\
\text { coefficient }\end{array}$ & ${ }^{*} 0.463$ & ${ }^{*} 0.445$ & ${ }^{*} 0.535$ & ${ }^{*} 0.474$ & ${ }^{*} 0.502$ \\
\hline & $\begin{array}{c}\text { Significance } \\
\text { level }\end{array}$ & 0.040 & 0.049 & 0.015 & 0.034 & 0.024 \\
\hline
\end{tabular}




\begin{tabular}{ccccccc}
\cline { 2 - 6 } Aiming precision from fall & $\begin{array}{c}\text { Correlation } \\
\text { coefficient } \\
\text { Significance } \\
\text { level }\end{array}$ & 0.444 & ${ }^{*} 0.453$ & ${ }^{*} 0.448$ & 0.430 & ${ }^{*} 0.463$ \\
\hline
\end{tabular}

Table 4 shows that there is a moral correlation between the types of accuracy of the hand ball throwing and the manifestations of attention where the coefficients of correlation.

Second: Find the predictive equations for both the accuracy of the shooting of the handball according to the manifestations of attention among the students of the Faculty of Physical Education and Sports Sciences Al-Qadisiyah University.

The researcher extracted the prediction equations using the statistical program SPSS. Predictive studies as they involve reaching more accurate results ${ }^{2}$ predictive equations for skill performance were extracted using the raw data method.

Table 4. Shows the correlation of each type of aiming with acceptable attributes of attention within the prediction equation.

\begin{tabular}{cccccccc}
\hline Variables & Correlatio & Coefficient of & Adjusted & Value $F$ & $1^{\text {st }}$ & $2^{\text {nd }}$ & Indication \\
& $n$ & variance R2 & ratio & degre & degree & level \\
& coefficient & & & e of & of & \\
$R$ & & & freed & freedo & \\
& & & & & om & $m$ & \\
& & & & &
\end{tabular}

The aiming precision from shoulder level

\begin{tabular}{|c|c|c|c|c|c|c|c|}
\hline $\begin{array}{l}\text { Attention } \\
\text { sharoness }\end{array}$ & 0.582 & 0.338 & .302 & 9.206 & 1 & 18 & .007 \\
\hline \multicolumn{8}{|c|}{ Aiming precision of jumping high } \\
\hline Focusing attention & 0.621 & 0.385 & .351 & 11.288 & 1 & 18 & .003 \\
\hline \multicolumn{8}{|c|}{ Aiming precision from jumping forward } \\
\hline Stability of attention & 0.535 & 0.286 & .246 & 7.205 & 1 & 18 & .015 \\
\hline \multicolumn{8}{|c|}{ Aiming precision from fall } \\
\hline Divert attention & 0.463 & 0.214 & .170 & 4.905 & 1 & 18 & .040 \\
\hline
\end{tabular}

Table (5) shows that there is a significant correlation between some types of aiming and attention attributes. Correlations were high and this means that the value of the correlation coefficient increases with the presence of these variables and the proportion of contribution increases.

2 Al-Zoghbi, M.\&al-Talafha,A.(2000).Statistical packages for social sciences. Amman, Jordan: Wael Amman House supported by the University of Jordan. 
Table 5. Shows the prediction equation for each type of aiming.

\begin{tabular}{|c|c|c|c|c|c|c|}
\hline $\begin{array}{l}\text { Mo } \\
\text { del }\end{array}$ & $\begin{array}{l}\text { variables Normal } \\
\text { laboratory }\end{array}$ & $\begin{array}{l}\text { Parameter } \\
\text { value }\end{array}$ & $\begin{array}{l}\text { Beta correlation } \\
\text { coefficient }\end{array}$ & $\begin{array}{l}\text { Calculated T } \\
\text { value }\end{array}$ & $\begin{array}{l}\text { Significanc } \\
\text { e level }\end{array}$ & $\begin{array}{l}\text { Statistical } \\
\text { function }\end{array}$ \\
\hline \multicolumn{7}{|c|}{ Aiming precision from shoulder level } \\
\hline \multirow[t]{3}{*}{1} & Constant & -8.816 & & -1.927 & .070 & Non - moral \\
\hline & Attention & 0.132 & .582 & 3.034 & .007 & moral \\
\hline & \multicolumn{6}{|c|}{ Aiming precision of jumping high } \\
\hline \multirow[t]{2}{*}{1} & Constant & 4.204 & & 3.397 & .003 & moral \\
\hline & Focusing attention & 0.484 & .621 & 3.360 & .003 & moral \\
\hline \multicolumn{7}{|c|}{ Aiming precision from jumping forward } \\
\hline \multirow[t]{3}{*}{1} & Constant & 2.659 & & .938 & .361 & Non - moral \\
\hline & Stability & 0.913 & .535 & 2.684 & .015 & Moral \\
\hline & \multicolumn{6}{|c|}{ Aiming precision from fall } \\
\hline \multirow[t]{2}{*}{1} & Constant & 3.715 & & 9.239 & .000 & moral \\
\hline & Divert attention & 0.092 & .463 & 2.215 & .040 & moral \\
\hline
\end{tabular}

The correlation coefficient increases with the presence of these variables and the proportion of contribution increases. To obtain the predictive equation for the types of aiming accuracy of the hand ball is to highlight what is in Table 6.

According to the table above, the predictive equation for the types of aiming in handball: For example, the prediction equation for the correction of jumping high: $y=w+m s$ since the:

$\mathrm{Y}=$ variable to be predicted and represents the correction skill and $\mathrm{w}=$ fixed amount.

Ms $=$ coefficient of the contributing variable $\times$ degrees of the independent variable in this way, the predictive equation of the aiming skills at the shoulder.

The correlation coefficient increases with the presence of these variables and the proportion of contribution increases. To obtain the predictive equation for the types of aiming accuracy of the hand ball is to highlight what is in Table 6.

According to the table above, the predictive equation for the types of aiming in handball: For example, the prediction equation for the correction of jumping high: $y=w+m s$ since the:

$\mathrm{Y}=$ variable to be predicted and represents the correction skill and $\mathrm{w}=$ fixed amount

Ms $=$ coefficient of the contributing variable $\times$ degrees of the independent variable in this way, the predictive equation of the aiming skills at the shoulder

$=4.204+(0,84 \times$ attention concentration $)=9,4036$ Note that the mean of the aiming from jumping high is 8,05 
We understand from this that the value of the coefficient of sharpness is $(0,132)$ and that the manifestations of attention (sharpness of attention) has contributed effectively to the aiming skill of the shoulder level, as the sharpness of attention is a special manifestation of attention important in handball because it contributes effectively to The success and improvement of the level of correction from the shoulder level and since the correction represents the outcome of technical performance and plans individual or collective and teams, it represents the skill to end the attack with all the skills involved in behaviour and whatever types and methods of performance, it performs one purpose, which is to cross the ball the entire circumference of the goal. ${ }^{3}$ It requires the player to have the intensity of attention towards the stimuli that he faces during the performance, therefore requires him nervous energy that can be lost during the activity involved in psychological processes, which occurs accurately, clearly and quickly ${ }^{4}$.

Also, the value of attention concentration factor is $(0,484)$.

One of the manifestations of attention is the concentration of attention, which has contributed effectively to the skill of shooting from jumping high, since this type of correction is performed from outside the freethrowing area $(9 \mathrm{~m})$ against the defensive wall formed by the defenders in front of the player ${ }^{5}$. Therefore requires the player to focus attention as it is psychological operations Which is implemented by the appropriate force of the stimuli associated with one type of activity and is not something that it performs automatically ${ }^{6}$ which is a society in the performance state with the focus is to gather ideas and stabilize attention to achieve the goal and if The concept of attention was a general focus gem? ${ }^{7}$.

As for the correction of jumping forward, the value of the factor of the stability of attention (0.913) and that the manifestation of attention is (stability of attention) has contributed an effective contribution to the correction skill of jumping forward and attributed the researcher that the attention to stability gives the possibility of the player to get rid of defenders And aiming strongly outside the line $(6 \mathrm{~m})$ and this way The distance between the striker and the goalkeeper is low, making it easier for the striker to direct the ball in the right place of the goal ${ }^{8}$.

Therefore, "the constancy of attention is the ability to keep sharp attention as long as possible As for the correction of the fall was the value of the correlation coefficient to divert attention $(0,092)$ and that the manifestation of attention is (divert attention) has contributed an effective contribution to the skill of the correction of the fall and help the player to approach the goal and used during the throw seven meters and lead to fall forward Or the player can change by falling aside left, right according to Z Of play ${ }^{9}$, so this requires performance divert attention from moving to another and from one influential case to another case it may return to the same point ${ }^{10}$.

\footnotetext{
3 Youssef,A.(2005). The effect of the final feedback types on learning the throwing skill from jumping high in hand ball. Babel, Iraq: Journal of Physical Education Sciences, Babylon University, Faculty of Physical Education.

${ }^{4}$ Al-Samad,A.(2000).The Physiology of Mental Operations. Baghdad, Iraq: Dar al-Fikr for Printing and Publishing.

${ }^{5}$ Raffek,V.\&others(1977). Handball Applied Practice, translated by Kamal Abdel Hamid. Cairo, Egypt: Dar El Maaref.

${ }^{6}$ Neidfer,R.(1990).The athletes' manual for mental training ,translated by Mohammad Reza lbrahim and others. Mosul, Iraq: Dar al-Hikma for printing and publishing.

${ }^{7}$ Mahjoub, W.(1989). Motion Science, Motor Learning. Baghdad, Iraq: University of Baghdad, House of Wisdom.

${ }^{8}$ Kassem,Q.\& Khamis,A.(2011).World Handball Encyclopedia.Beirut, Lebanon:Arab Book House.

${ }^{9}$ Kassem,Q.\& Khamis,A.(2011).World Handball Encyclopedia.Beirut, Lebanon:Arab Book House.

${ }^{10} \mathrm{Ahmad}, \mathrm{S}$. (1988). The relationship of concentration of attention to accuracy in free throw in basketball. Iraq: Faculty of Physical Education, University of Baghdad.
} 


\section{RECOMMENDATIONS}

1. Work to develop the manifestations of attention through training units and the development of types of aiming hand reel.

2. The need to note the development of the manifestations of attention among students, which helps to retain the skill of correction handball.

3. Further research in this regard on the manifestations of attention in other events.

\section{REFERENCES}

Ahmad,S. (1988). The relationship of concentration of attention to accuracy in free throw in basketball. Iraq: Faculty of Physical Education, University of Baghdad.

Al-Badri, J.\&Al-Sudani, A. (2011).World Handball Encyclopedia. Beirut, Lebanon: Safa Foundation for Publications.

Al-Khayat,D.\&Qassem,A.(1988).Handball. Mosal, Iraq: Dar Al-Fikr for Printing and Publishing, University of Mosul.

Al-Samad,A.(2000).The Physiology of Mental Operations. Baghdad, Iraq: Dar al-Fikr for Printing and Publishing.

Al-Zoghbi, M. \&al-Talafha,A.(2000).Statistical packages for social sciences. Amman, Jordan: Wael Amman House supported by the University of Jordan.

Kassem,Q.\& Khamis,A.(2011).World Handball Encyclopedia.Beirut, Lebanon:Arab Book House.

Mahjoub, W.(1989). Motion Science, Motor Learning. Baghdad, Iraq: University of Baghdad, House of Wisdom.

Mohsen,B.\& Sami,N.(1984).Study of the manifestations of attention to the players of different lines of football. Alexandria, Egypt: Research the first scientific conference, Faculty of Physical Education, Helwan University.

Mtaib,S. (1997).Design battery test to measure the basic skills of handball. Iraq: Baghdad University, Faculty of Physical Education.

Mustafa.H. \& Mohammed, M. (1989). Attitudes of Athletes in Sports Activities (Comparative Study). Egypt: Scientific Journal of Physical Education and Sports, Faculty of Physical Education for Boys.

Neidfer,R.(1990).The athletes' manual for mental training ,translated by Mohammad Reza Ibrahim and others. Mosul, Iraq: Dar al-Hikma for printing and publishing.

Raffek,V.\&others(1977). Handball Applied Practice, translated by Kamal Abdel Hamid. Cairo, Egypt: Dar El Maaref.

Youssef,A.(2005). The effect of the final feedback types on learning the throwing skill from jumping high in hand ball.Babel, Iraq: Journal of Physical Education Sciences, Babylon University, Faculty of Physical Education.

\section{(ㅇ) $(\mathbb{Q} \Theta \Theta$}

This work is licensed under a Attribution-NonCommercial-NoDerivatives 4.0 International (CC BY-NC-ND 4.0). 